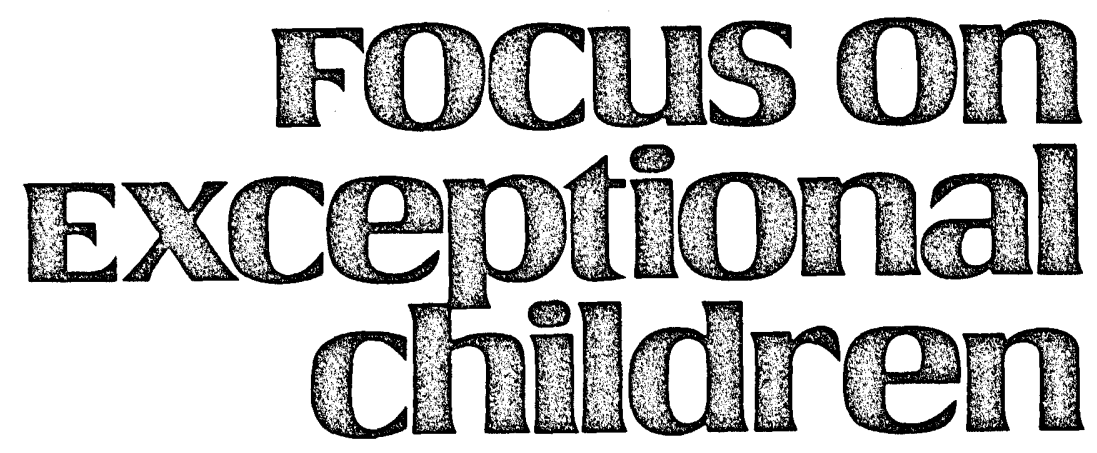

\title{
Composition Instruction with Learning Disabled Students: Self-Instructional Strategy Training
}

\author{
Steve Graham, Karen R. Harris, and Richard Sawyer
}

Writing is a particularly complex and demanding task. The development of skillful writing requires much more than simply adding special knowledge and skills to existing oral language abilities (Scardamalia \& Bereiter, 1986). The beginning writer must develop the ability to generate language in the absence of a conversational partner, activate relevant memories without prompting, generate units of text larger than typically included in a conversational turn, and examine what is generated from the perspectives of both the writer and the reader (Bereiter \& Scardamalia, 1983).

Furthermore, the beginning writer must learn to monitor and regulate a variety of mental operations including the generation of ideas, development of plans for writing, and the actual production of text that corresponds to the conventions of standard written English. The developing writer, in sum, must learn to orchestrate a variety of cognitive activities, and attention must be allocated to both mechanical and substantive concerns in an efficient, effective manner (Bereiter \& Scardamalia, 1982; Graham, 1982; Scardamalia \& Bereiter, 1986).

One way to help poor and beginning writers overcome the difficulties inherent in the composing process is to teach them task-specific and metacognitive strategies for regulating their writing behavior (Graham \& Harris, 1987a; Harris \& Graham, in press). Such an approach may be particularly helpful because strategy instruction can be employed as a means for helping students gain more security and competence in the processes considered central to effective writing (e.g., planning, revising). Furthermore, strategy training holds much promise as a means for helping students develop the skills necessary to carry out more mature and complex composing behaviors (Graham \& Harris, in press-a, in press-b).

Strategy and self-regulation training may be especially useful as a means for helping learning disabled (LD) students improve their writing performance. Two assumptions underlying strategy instruction are (Graham \& Harris, in press-b; Harris, 1982):

1. Students should be active collaborators in the learning process.

2. Instruction designed to alter a student's cognitions, as well as behaviors, is an effective approach, because cognitive activity mediates behavior.

Similarly, writing necessitates active task involvement and evokes a variety of complex mental operations.

Steve Graham is an Associate Professor, Karen Harris is an Assistant Professor, and Richard Sawyer is a Doctoral Candidate, all with the Department of Special Education, University of Maryland. 
LD students, however, have been characterized by a lack of active task engagement and persistence (Harris, 1986a, 1986b), and they appear to have difficulty executing and monitoring the cognitive processes central to effective writing. For example, in a recent review, Graham and Harris (in press-b) concluded that LD students have difficulty generating, planning, framing, producing, and revising text. Their written products are inordinately short (cf. Deno, Marston, \& Mirkin, 1982; Nodine, Barenbaum, \& Newcomer, 1985), frequently lack many of the basic structural elements common to the type of writing tasks they are assigned (cf. Englert \& Thomas, 1987; Graham \& Harris, $1987 \mathrm{~b}$ ), and are replete with errors related to the standard production of written language (cf. Deno et al., 1982; Moran, 1981; MacArthur \& Graham, in press). Furthermore, LD students perform little advanced planning even when prompted (MacArthur \& Graham, in press), treat the writing task as simply telling whatever comes to mind (Englert \& Raphael, in press), and make only minor, surfacelevel changes (e.g., punctuation, spelling) when asked to

\section{FOCus on Exceptional children}

FOCUS ON EXCEPTIONAL CHILDREN (ISSNO015-5IIX) (USPS 203-360) is published monthly except June, July, and August as a service to teachers, special educators, curriculum specialists, administrators, and those concerned with the special education of exceptional children. This publication is annotated and indexed by the ERIC Clearinghouse on Handicapped and Gifted Children for publication in the monthly Current Index to Journals in Education (CIJE) and the quarterly index, Exceptional Child Education Resources (ECER). It is also available in microform from Xerox University Microfilm, Ann Arbor, MI. Subscription rates: Individuals, $\$ 24$ per year; institutions, $\$ 30$ per year. Copyright (1) 1987, Love Publishing Company. All rights reserved. Reproduction in whole or part without written permission is prohibited. Printed in the United States of America. Second class postage is paid at Denver, Colorado.

POSTMASTER: Send address changes to:

Love Publishing Company

Executive and Editorial Office

1777 South Bellaire Street

Denver, Colorado 80222

Telephone (303) 757-2579

EDITORIAL BOARD

Edward L. Meyen

University of Kansas

Richard J. Whelan

University of Kansas Medical Center

Stanley F. Love Publisher
Carolyn Acheson Senior Editor revise their text (MacArthur \& Graham, in press). Consequently, given the nature of writing and the writing characteristics of LD students, strategy training provides a good match to both the task and the characteristics of the students under consideration.

Although research on the use of strategy training for improving the writing skills of LD students and other poor writers is still in its infancy, results presented to date have been promising. Students with poor writing skills have been successfully taught to employ strategy and self-regulation procedures to augment active task engagement, activate a search of appropriate memory stores for writing content, enact purposeful control over actual text production, execute specific composition strategies, facilitate advanced planning, and increase both the quantity and quality of text revisions (see Graham \& Harris, 1987a; in press-b).

Further objectives for strategic composition interventions with LD students have been suggested by Graham and Harris (in press-b). They proposed that LD students' difficulties in generating, planning, framing, producing, and revising text may be a result of one or more of the following factors:

1. LD students may not be sufficiently knowledgeable regarding the topics they are asked to write about, or they may not effectively access knowledge they do possess.

2. They may not be adequately knowledgeable about the characteristics of different types of writing genres (e.g., purposes, conventions, types of content), or ineffective in retrieving the genre-specific knowledge they do have.

3. The mechanical demands of text production (e.g., capitalization, spelling) may interfere with more substantive writing processes such as planning, framing, or revising text.

4. LD students may use ineffective (or no) strategies when engaging in writing processes such as generating, framing, or revising text.

5. LD students' writing problems may result from difficulties with executive control; processes and strategies must be brought into play at the right time and in proper relationship to each other.

Strategy instruction may be helpful in addressing, at least in part, each of these factors. Specifically, students can be taught strategies for independently accessing topic-specific knowledge for writing content, as well as knowlege of different discourse types. Routines designed to enhance students' intentional control over text production can be placed into operation. Students also can be taught powerful 
strategies for framing, planning, and revising their compositions. Finally, students can receive instruction aimed at develping competence in regulating both their own behavior during writing and the mental operations underlying the writing process.

In this article we describe the self-instructional strategy training procedures that we have developed for teaching these composition skills (as well as other academic skills) to LD students. First, an overview of important contributions to cognitive strategy training and their influence on our specific training regimen are presented. This is followed by an examination of the specific composition strategies we have developed and field-tested. Finally, self-instructional strategy training is illustrated through a detailed presentation of how students were taught one of the composition strategies (the story grammar strategy for creative writing).

\section{COGNITIVE STRATEGY TRAINING}

The development of our training regime, self-instructional strategy training, has been influenced by three important cognitive strategy training roots: cognitive-behavior modification (Meichenbaum, 1977), self-control training (Brown, Campione, \& Day, 1981; Brown \& Palincsar, 1982), and the learning strategies model for severely learning disabled adolescents developed at the University of Kansas Institute for Research in Learning Disabilities (Schumaker, Deshler, Alley, \& Warner, 1983).

The cognitive-behavior modification approach stresses interactive learning between teacher and student, with ultimate responsibility for recruiting, applying, and monitoring strategies gradually transferred to the student (Meichenbaum, 1976, 1977). Sound instructional procedures such as initial teacher guidance, modeling, active learner engagement, graduated difficulty, prompts, corrective feedback, and reinforcement are incorporated into training (Harris, 1982). Based on cognitive-behavioral theory, Meichenbaum developed self-instructional training, which has four basic strategy acquisition steps. First, the teacher describes and models task-specific and metacognitive strategies aloud while performing the task. Second, the student performs the task using the same or similar self-instructions with decelerating teacher feedback and guidance over practice sessions. Third, the student performs the task independently using overt self-instructions. Fourth, the student independently performs the task using covert (internal) verbalizations.

At least six types of self-instructions can be developed to help the student activate and regulate appropriate strategies to mediate behavior and complete the task: (a) problem definition (What is it I have to do?), (b) focusing of attention (Take my time . . . look carefully), (c) planning and response guidance (First I need to write down the steps), (d) self-reinforcement (Good-I like that idea!), (e) selfevaluation (Do I have all the story parts?), and (f) coping and error-correcting options (I forgot one part, but that's $\mathrm{OK}$-I can revise this). Self-instructional training was initially developed to help impulsive children gain control over their response behavior; our self-instructional strategy training procedures were developed to apply self-instructional training to academic content areas.

We also were influenced by the concept of self-control training developed by Brown and her colleagues (Brown et al., 1981; Brown \& Palincsar, 1982). This intervention approach includes skills training (instruction in task-specific strategies), metacognitive training (instruction in the selfregulation of those strategies), and instruction in the significance and potential of the trained strategies. Brown and her colleagues have argued that when students receive instruction in task-specific strategies, without self-regulation training and instruction in the importance of the strategies, they may fail to independently produce an effective strategy because they do not understand how and when to apply the strategy or they may fail to recognize that strategy usage meaningfully improves their performance.

It also has been argued that instruction in explicit self-regulation procedures (goal-setting, self-monitoring, self-assessment, self-recording) is particularly important in obtaining maintenance and generalization of learned strategies, as well as in improving students' self-perceptions (Graham \& Harris, 1987b; Pressley \& Levin, in press). Learning disabled students with whom we have worked have frequently identified graphing of their performance (self-recording) as one of their favorite components in strategy training (Graham \& Harris, 1987b; Harris \& Graham, 1985). Thus, selfinstructional strategy training typically includes explicit selfregulation components.

Finally, Deshler and his colleagues validated a series of acquisition steps for teaching strategies to students with severe learning disabilities (Deshler, Alley, Warner, \& Schumaker, 1981). Their teaching methodology provides students with the knowledge, motivation, and practice needed to apply, maintain, and generalize the use of a specific strategy.

\section{Self-Instructional Strategy Training}

Self-instructional strategy training incorporates components from each of these three roots and from our own 
training experiences. Seven basic, but flexible, steps provide the barebones framework of self-instructional strategy training:

1. Pretraining.

2. Review of current performance level.

3. Description of the strategy.

4. Modeling of the strategy and self-instructions.

5. Mastery of the composition strategy.

6. Controlled practice of the strategy and self-instructions.

7. Independent performance.

Procedures for promoting generalization and maintenance, as well as for evaluation, are embedded throughout the training steps.

The seven training steps typically proceed as follows. First, any preskills necessary for understanding, acquiring, and executing the targeted composition strategy that are not already present in the student's repertoire are developed. Second, the instructor and student examine and discuss baseline data and strategies that the student currently uses. They then discuss the significance and potential benefits of the proposed training; commitment to participate as a partner and to attempt the strategies is established. Any negative or ineffective self-statements or strategies the student is currently using can be discussed. Specific self-regulation procedures also may be introduced at this point. Third, the instructor describes the composition strategy and its purposes and outlines how and when to use it.

Fourth, the instructor models the strategy and self-instructions (including problem definition, self-evaluation, coping and error correcting, and self-reinforcement) using language appropriate to the student. After discussing the model's performance, the student generates and records his or her own self-statements for each type of self-instruction. Fifth, strategy steps are memorized; strategy steps may be paraphrased as long as the original meaning is preserved. Sixth, the student practices the strategy and self-instructions while performing the writing task. Teacher guidance and physical prompts (such as strategy charts) are faded over practice sessions as the student independently reaches criterion. Criterion levels are gradually increased until the final objective is met. Any specific self-regulation procedures (e.g., goal-setting, self-assessment, self-recording) that have been decided upon are used throughout this sixth step. Seventh, the student is encouraged to use the strategy and self-instructions independently with covert (internal) speech.

Self-regulation procedures are continued but can be faded. The instructor continues to monitor performance. Through- out training, the instructor and student discuss opportunities to utilize the strategy and self-instructions in other tasks and settings. Teachers and parents are asked to comment on compositions. Students are encouraged to cooperatively involve their teachers and employ the training procedures in their mainstream classrooms.

\section{Developing Composition Training}

Before training can begin, an effective composition strategy (or set of strategies) must be determined. Although teachers may be able to locate some composition strategies by consulting the literature, they frequently will have to develop or modify strategies for their own needs. Great care must be taken to ensure that the selected or devised strategy works; well intentioned indivduals may unwittingly teach strategies that do not work well (Pressley \& Levin, in press). Careful learner and task analyses should be conducted to determine training goals, select training tasks, and establish both the strategy or strategies to be taught and a sequence of learning activities (Graham \& Harris, 1987a; Harris, 1982). Developing composition strategy training is illustrated in Figure 1.

\section{Learner Analysis}

Characteristics of the learner(s), such as age, cognitive capacity and competence, language development, attributions and beliefs, expectancies and attitudes, learning style, internal dialogue, and initial knowledge state and strategy use, may interact with task and training requirements and should be carefully considered. For example, younger students or those with severe written language deficits may require more prolonged pretraining, more explicit training procedures and components, simpler strategies, and more externally based and frequent reinforcement. Or students who exhibit maladaptive attributions, negative self-perceptions, or poor attitudes may require self-statements and training components aimed at developing an internal locus of control and a stronger sense of self-efficacy. Cognitive, affective, and behavioral characteristics of students can be targeted for change or development during training; the targets of training should depend upon the learner and task analyses. Training goals, however, should be kept to within reasonable expectations.

\section{Task Analysis}

In conjunction with the learner analysis, the composition task requires careful analysis. First, the teacher must clearly 


\section{FIGURE 1 \\ Developing Self-Instructional Strategy Training}

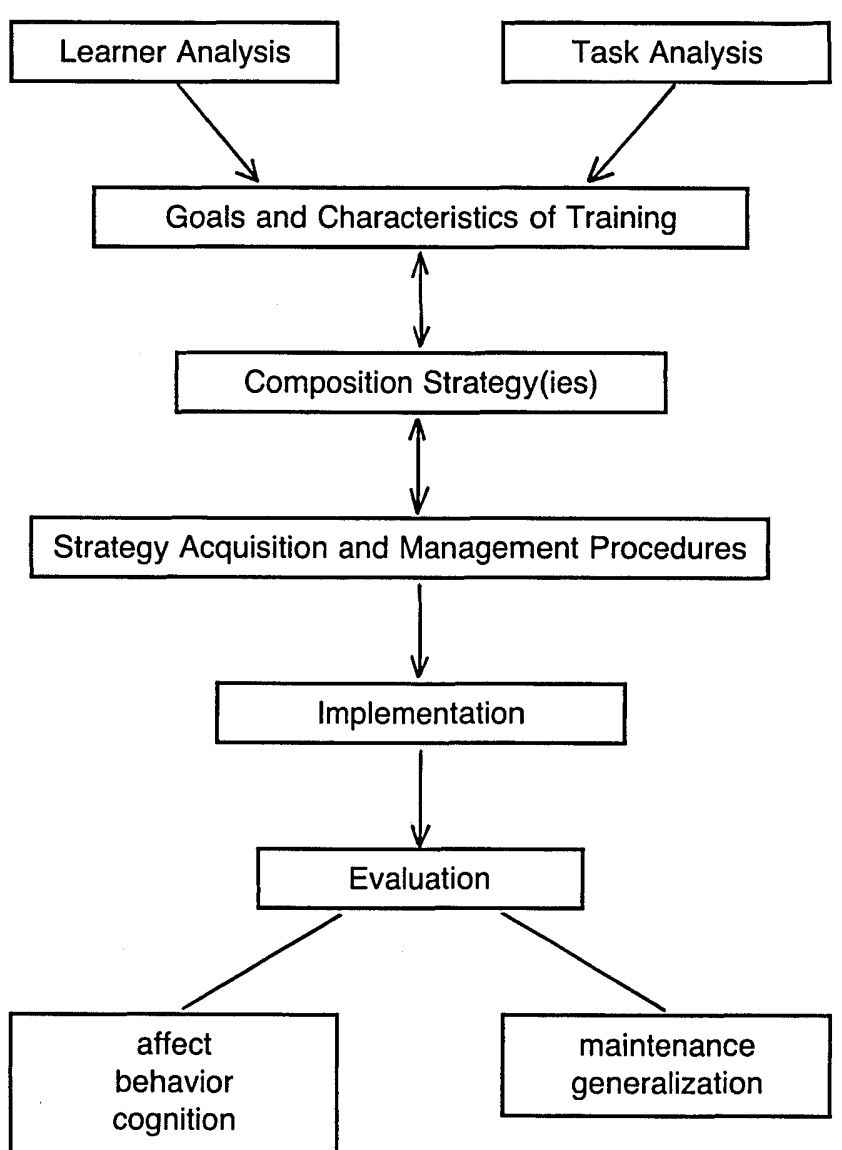

specify the goals of training. The targeted composition skills must be important enough to effect a reasonable change in the students' writing performance, yet must not be beyond students' capabilities. Furthermore, the psychological demands of the task and the sequential, organized cognitions that the student must engage in to perform adequately also have to be analyzed (Meichenbaum, 1976). For example, as the composition strategy taught becomes more complex, greater demands are placed on the students' memory and information-processing abilities. The teacher also may need to consider the level of frustration likely to be induced by training. A mnemonic may be helpful in alleviating or moderating these demands, as may charts or other prompts.

In analyzing the task, it may be helpful to observe and question competent writers (students or adults, including the teacher) performing the task. These experts can report on helpful strategies and cognitions (self-statements, images, perceptions, beliefs) that they employ. Cognitions necessary for comprehension of the composition task, the production of appropriate strategies, and the monitoring of these strategies should be considered. The teacher also might observe and interview students who perform poorly on the task in order to speculate on factors that lead to poor performance.

\section{Characteristics of Training}

Once learner and task analyses have been conducted, the teacher can select strategy and self-regulation components appropriate to the learners, tasks, and goals of training. The characteristics (or hows) of training, as well as the components of training, however, must be considered. Training should emphasize the role of students as active collaborators and interaction between teacher and students; principles of interactional scaffolding and Socratic dialogue should be incorporated (Graham \& Harris, 1987b; Meichenbaum, 1977). The teacher should be enthusiastic and responsive to each student and should provide individually tailored feedback. Strategies should be overtly and explicitly modeled in context; the goal and significance of the strategies should be clear. The teacher initially provides strong external support to students; responsibility for recruiting, executing, and monitoring strategies is gradually placed upon the student. Training is meant to enhance conscious executive control of the target strategy, as well as to promote motivation by providing students with the skill as well as the will to use the targeted strategy. Finally, training should be criterion-based rather than time-based; students are required to master each step of training before proceeding to the next.

\section{Evaluation of Training}

Evaluation of strategy and skill development, as well as other affective, cognitive, and behavioral changes that may occur, takes place throughout training, at the culmination of training, and in generalization and maintenance conditions. For example, various assessment procedures may be used to ascertain improvements in students' frustration tolerance, persistence, on-task behavior, attributions, self-efficacy, and so on (Harris, 1985). Sufficient time should be allowed for demonstration of training effects, as some changes may take time to manifest. Research also indicates that booster sessions probably will be necessary for longterm maintenance (Harris \& Graham, 1985; Meichenbaum, 1977). It is important to continue assessing strategy use after students are performing independently; students may 
either effectively modify or actually subvert the original strategy taught (Harris, 1982; Wong, 1985). Finally, the teacher and students should regularly assess their satisfaction with the training procedures and strategies.

\section{COMPOSITION STRATEGIES}

Currently, four specific writing strategies have been developed and taught via self-instructional strategy training. These have been designed to enable students to increase vocabulary diversity in their compositions, generate writing content and plan a composition in advance, and revise and edit texts. Explicit rules and steps for executing specific writing tasks (e.g., creative short story, argumentative essay) and procedures for student self-direction of attention and resources are incorporated in each strategy. Use of the strategies may ease the executive burden of writing by minimizing the attention that a student must apply in carrying out a specific cognitive process, such as searching memory for relevant genre-specific content.

\section{Vocabulary Diversity}

In an initial study (Harris \& Graham, 1985), the effects of strategy plus self-regulation training on LD students' ability to include action verbs, adverbs, and adjectives in a creative short story were investigated. Specifically, we sought to increase both the number and diversity of these vocabulary items with a strategy training package that included mastery of a five-step composition strategy, self-instructional statements, and self-regulation procedures. The composition strategy, illustrated here with adjectives, directed the student to: (a) look at the picture (stimulus item) and write down good describing words, (b) think of good story ideas to use these words in, (c) write the story-use good describing words and be sure the story makes sense, (d) read back over the story (Did I write a good story?) and (e) fix the story (Can I use more good describing words?).

The self-instructional statements included prompts and questions designed to facilitate generation of the target items through brainstorming (e.g., Think of good words; let my mind be free), problem definition (e.g., What is it I have to do? What kinds of words do I need to use?), self-evaluation (e.g., Am I doing a good job? Have I included all the word types?), and self-reinforcement (e.g., I'm doing good work; my story is going to be good).

Following the student's mastery of the strategy and self-instrutional statements, the self-regulation component of the training package was introduced. Prior to writing, students set specific goals regarding the number and diversity of vocabulary items for inclusion in their stories. Once the story was completed, students graphed and evaluated their performance and then set a new goal for their next story.

Stories written by all students after training evidenced substantial increases above baseline levels in number and diversity of action verbs, adverbs, and adjectives. Additionally, posttraining stories were considerably longer and received higher quality ratings than pretraining stories. Increases in story length did not appear to result solely from increases in the target vocabulary items. Training procedures appeared to elicit not only the production of action verbs, adverbs, and adjectives, but the generation of other story content as well. The process of listing target vocabulary words prior to writing may stimulate additional content generation by supplying students with an executive strategy for carrying out a self-directed memory search (Graham \& Harris, in press-b). Additionally, increases in story length and vocabulary diversity may have, in part, been responsible for improvement in story quality. In another study (MacArthur \& Graham, in press), both of these indices were found to be related to the overall quality of stories composed by LD students.

Harris and Graham (1985) also found that students obtained generalization from the training setting to the special education resource room and that training effects were maintained for up to 6 weeks. A follow-up probe collected $31 / 2$ months after training, however, indicated mixed results; long-term maintenance and transfer were found for only one of the three vocabulary variables. Nevertheless, the students had remembered all of the strategy steps and the different vocabulary items. Consequently, the application of a booster session would likely have returned performance rates to their initial posttraining levels.

\section{Content Generation and Advanced Planning}

In two subsequent studies (Graham \& Harris, 1987b; Harris \& Graham, 1987), strategies designed to affect what students do prior to composing and during the actual writing process were investigated. As mentioned, LD students do little advanced planning, demonstrate difficulty generating content, and frequently produce written products that do not represent the type of composition under consideration. Thus, much of our recent effort has been aimed at developing and testing strategies designed to augment advanced planning and content generation with the stipulation that the search for writing content be dictated by the primary structural features reflective of specific literary genres-narrative, argumentative, and so forth. 
In a study by Graham and Harris (1987b), 22 fifth- and sixth-grade LD students were taught (in groups of two or three) a strategy for developing and writing a narrative story. The strategy had five steps: (a) Look at the picture (stimulus item), (b) let your mind be free, (c) write down the story part reminder (W-W-W; What $=2$; How $=2$ ), (d) write down story part ideas for each part, and (e) write your story-use good parts and make sense. Using the mnemonic in the third step, students prompted themselves with seven self-generated questions to produce story content regarding common story elements:

-Who is the main character; who else is in the story?

-When does the story take place?

-Where does the story take place?

- What does the main character do?

- What happens when he/she tries to do it?

- How does the story end?

- How does the main character feel?

Students were directed to use the generated content as a schematic blueprint for their stories. Students also generated and practiced using self-instructional prompts for promoting brainstorming, problem-definition, self-evaluation, and selfreinforcement. Finally, explicit self-regulation procedures, including goal-setting, self-assessment, and self-recording using a graph, were taught to half of the subjects.

Self-instructional strategy training meaningfully improved LD students' creative writing behavior. The schematic structure of stories written after training evidenced significant improvement. Prior to training, only $36 \%$ of LD students' stories included at least six common story elements. Following training, $86 \%$ of the stories met this same criteria. A contrast group of normally achieving, competent writers provided an index of educational validity. Whereas, prior to training, LD students were significantly less adept than their peers at incorporating story grammar elements into their compositions, after training their performance was indistinguishable from that of age-appropriate skilled writers. Furthermore, stories written after training received significantly higher quality ratings than did pretraining stories. Students' confidence in their ability to write a good story also improved; self-efficacy ratings were substantially higher following training.

Finally, training effects generalized to a new classroom setting and were maintained 2 weeks after treatment. Anecdotal evidence of generalization also was obtained; subjects reported using or adapting the strategy for other types of writing assignments, for reading stories, and for writing outlines. Several subjects also brought in stories they had written at home. The social validity, or acceptability, of this composition training was high among teachers and students. Students who used the self-assessment and graphing procedures evaluated them enthusiastically. The explicit self-regulation procedures, however, did not produce augmental effects on any of the measures of writing performance or on self-efficacy.

In another study (Harris \& Graham, 1987), the effects of strategy training in facilitating advanced planning and content generation was further investigated. Similar to the Graham and Harris (1987b) study, students were taught to produce writing content in relation to a specific genre; argumentative essays were chosen as the writing topic of interest. Additionally, students were asked to evaluate writing content by considering the potential reader(s) of their text, as well as reasons for writing their compositions. Further, it was noted in the story grammar training study (Graham \& Harris, 1987b) that in several cases what students had written prior to actual story writing was in sentence form and either closely or exactly resembled the end product. As a result, in the Harris and Graham (1987) study, students were encouraged to generate notes during the advanced planning process and to expand on these notes while actually writing their essays.

Three steps comprised the basic strategy in the Harris and Graham (1987) study:

1. Think, who will read this, and why am I writing this?

2. Plan what to say using TREE (note topic sentence, note reasons, examine reasons, note ending).

3. Write and say more.

As in the two previous studies, students developed and practiced self-instructional prompts for brainstorming, problem definition, self-evaluation, and self-reinforcement.

Although data analysis is presently in progress, preliminary results are positive. Following training, essays composed by sixth-grade LD students evidenced marked improvements above baseline levels in the number of elements (premise, reasons, elaborations, examples, and conclusions) incorporated in the compositions. Results generalized from the resource room to the students' regular classroom and maintained over a 6 -week period.

Furthermore, the possible transfer effects of training to a second genre, narrative stories, was investigated. At the completion of training, the examiner and students discussed how the three-step strategy (excluding the mnemonic TREE) might be used with narrative story writing. Results have been equivocal. For example, one student's narrative stories did not demonstrate transfer effects, while another student's 
stories, though lacking in many of the commonly included story grammar elements, were substantially improved. As a result, a booster session was implemented in which students received practice in using the mnemonic SPACE (note setting, purpose, action, conclusion, and emotion) during the second step of the strategy. Following the booster session, the student's stories improved considerably.

Examples of typical compositions from the Graham and Harris (1987b) and Harris and Graham (1987) studies are presented in Table 1. These compositions help to illustrate the effectiveness of training.

\section{Revising and Editing}

The final study conducted to date involved instructing sixth-grade LD students to revise and edit essays composed on a microcomputer (Graham \& MacArthur, 1987). The revisions that $L D$ students make rarely alter or significantly improve the meaning of their first drafts (MacArthur \& Graham, in press). LD students, however, have been found to be adept in using text editing operations for adding material when composing at the microcomputer. With these points in mind, the following 6-step strategy was developed: (a) Read your essay, (b) find the sentence that tells what you believe-is it clear, (c) add two reasons why you believe it, (d) SCAN each sentence (does it make sense; is it con- nected to my belief; can I add more; note errors), (e) make changes on the computer, and (f) re-read the essay and make final changes.

Baseline and posttraining writing probes were collected; students composed a first draft and revised it the following day. During baseline, students averaged only two to three revisions per essay, and the majority of these alterations involved surface-level and word changes. The meaning of what was written was affected in only a small percentage of revisions (average range of $14 \%$ to $31 \%$ ), and the quality of students' essays was essentially unchanged. Training, however, dramatically improved students' revising behavior. They averaged six to 10 revisions per essay, the majority of which involved phrase and T-unit changes. Substantially more revisions affected meaning (average range $41 \%$ to $83 \%$ ), and this was accompanied by dramatic improvements in overall quality. Also, posttraining essays were much longer, and all of the noted effects were maintained over time.

In summary, self-instructional strategy training can be successfully used to teach a variety of different writing strategies to LD students. Training in our studies has been conducted either individually or in small groups of up to three students. Teachers with whom we have worked have used these or similar strategies successfully with groups of up to 10 students.

\section{Story Grammar Strategy (Graham \& Harris, 1987b)}

\section{Pretraining:}

One day I was running in the field. It was very hot and leaves was falling. There are lots of hills and nice green grass. There are huge trees thats full of leaves. There were lots of flowers in the garden. It was a lot of shade. Lots of bushes that has leaves on it. And the summer was nice.

\section{Posttraining:}

Once upon a time a Indian named Rob wanted to ride a horse again. The reason why Rob wanted to ride again is because two years ago, he had an accident on the horse. Rob had got hurt bad. He had to get his legs cut off. So one day Rob went outside in his wheelchair and he seen a horse. It was all white and then Rob wheeled his chair over to the horse. And Rob grabbed the horse and pulled his self up. Rob was on the horse. Then the horse took off. And the horse was kicking and then he jumped up and Rob the brave Indian fell off and died. He was brave so that is the end of him.
Essay Strategy (Harris \& Graham, 1987)

\section{Pretraining:}

(writing prompt-Do you think children should have to go to school in the summer?) No, because we went to for 180 and we need to have fun in the summer and rest our brains before we start school again.

\section{Posttraining:}

(writing prompt-Are school rules necessary?) I think they are necessary. If there were no rules, people would be doing whatever they want. Not listening to the teacher and eating gum and candy and screaming and jumping on the furniture. That is why we have rules. So the kids can obey them and we will have a nice school. So that is why 1 think rules are necessary.

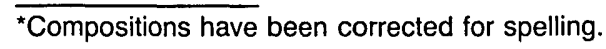




\section{CREATIVE WRITING: THE STORY GRAMMAR STRATEGY}

Prior to training in the story grammar strategy (Graham \& Harris, 1987b), students should compose one or two creative short stories to provide the necessary baseline data. Learner and task analyses should be conducted carefully, as this information is critical to enhancing the effectiveness of training. Important to self-instructional strategy training are flexibility and individualization in the selection and tailoring of components and procedures. For example, in some cases step 1 may not be needed, and training may begin at step 2, or the first two steps may be reversed. The self-regulation procedures can be presented at any of several steps, depending upon the teacher's knowledge of the students and evaluation of their progress and readiness for these procedures. The following steps and procedures were successful with the students and teachers with whom we worked.

\section{Step 1: Pretraining}

Pretraining focused on defining, identifying, and generating story grammar elements. A small chart provided the mnemonic: W-W-W; What $=2$; How $=2$, for the seven story grammar questions: (a) Who is the main character; who else is in the story? (b) when does the story take place? (c) where does the story take place? (d) what does the main character do? (e) what happens when he/she tries to do it? (f) how does the story end? and (g) how does the main character feel? Students practiced the story grammar mnemonic in various ways (chart present, chart absent; group rehearsal, partner testing, etc.). Both the mnemonic and the meaning of each element had to be mastered without prompts before proceeding to the next step, but the seven questions had to be reviewed during steps 2 and 3 .

\section{Step 2: Review Current Performance Level and Training Rationale}

The instructor and students examined students' previously written stories for both inclusion and quality of the story grammar elements. The instructor and students also discussed the goal of training (to write better stories), why this is important, and how inclusion and expansion of the story grammar elements improve a story. Students received a graph depicting the number of story grammar elements included in their previous stories. The instructor explained and demonstrated for the students how they would continue to use the graph for self-recording throughout training.

\section{Step 3: Describe the Learning Strategy}

A small chart was used to introduce and discuss the fivestep strategy for writing good stories: (a) Look at the picture, (b) let your mind be free, (c) write down the story part reminder (mnemonic), (d) write down story part ideas for each part, and (e) write your story; use good parts and make sense. The instructor and students also discussed and modeled creativity self-statements (e.g., Let my mind be free; think of fun ideas) helpful in thinking of good story parts. Students generated their own preferred creativity self-statements, recorded them on paper, and practiced using these self-statements to generate story parts.

\section{Step 4: Model the Strategy and Self-Instructions}

The two charts, the list of creativity self-statements, and a new stimulus picture were set out. The instructor modeled the writing strategy by writing a story while "thinking out loud." Students were allowed and encouraged to "help." The instructor modeled four additional types of self-instructions while composing: problem definition (What is it I have to do? I need to-), planning (including the five strategy steps), self-evaluation (How am I doing?) and self-reinforcement (I like this part). After modeling, the instructor and students discussed the importance of what we say to ourselves while we work. Students provided examples of personal positive (and negative, if volunteered) self-statements and then generated and recorded their own examples of the four types of self-instructions.

\section{Step 5: Mastery of Strategy Steps}

Students were required to practice, in ways similar to those used in step 1, the five-step writing strategy until it was memorized. Paraphrasing was allowed as long as meaning remained intact.

\section{Step 6: Controlled Practice}

The instructor and students conjointly composed a story using the five-step strategy and self-instructional statements. The mnemonic and five-step strategy charts, as well as the student-generated self-instruction lists, were set out as prompts. Though the instructor directed and monitored the process, she did not write the story. The students and instructor initially set a goal to include all of the story grammar elements in their composition. Following completion of the story, the students and the instructor independently counted the number of story elements included in their story, com- 
pared counts, graphed the number on each student's chart, and compared performance to the criterion.

This step was repeated as necessary, using new stimuli pictures, until the students became proficient in using the strategy and overt self-instructions. Individually tailored positive and corrective feedback was provided as necessary, and the teacher began encouraging students to use covert speech. The goal-setting, self-assessment, and self-recording procedures were enacted for each story written.

\section{Step 7: Independent Performance}

Students independently composed stories using the fivestep strategy and self-instructional statements. Positive and corrective feedback again was provided as needed; transition to covert self-instruction was encouraged. Students were allowed to use the charts and self-instruction list only for the first story written. The goal-setting and self-monitoring procedures were continued independently.

\section{Generalization and Maintenance Components}

Research-based suggestions for enhancing durability and generalization are embedded throughout the training procedures (cf. Harris, 1982). Additionally, students were asked to share with their teachers and parents what they were learning, and to have the resource room teacher initial each practice story completed. Students also discussed with their instructors how this learning could be used in their resource and regular classrooms. If necessary (although not done in this study), behavioral contracts and cooperative planning with other teachers might also be used to facilitate transfer and maintenance.

\section{CONCLUDING COMMENTS}

Self-instructional strategy training procedures can be applied to a variety of composition tasks and skills. Strategy training procedures, however, should not be used to displace traditional writing pedagogy or other remedial instructional methods that have proven to be effective. Rather, strategy training procedures should be integrated as part of a total writing curriculum designed to facilitate student performance in a wide spectrum of writing skills, ranging from automatization of lower-level skills of getting language onto paper, to the use of writing as a sophisticated means of expressing, exploring, and extending thought (see Graham $\&$ Harris, in press-c, for a discussion of writing programs for exceptional children).
Likewise, strategy training procedures may not be appropriate for all students. Both normally achieving and exceptional students exhibit a wide range of writing performance. For example, a few students labeled LD with whom we have worked demonstrated writing skills similar to their normally achieving counterparts. In contrast, we also have encountered fifth- and sixth-grade LD students who were unable to compose even one coherent sentence. For the first group of students, strategy training procedures may be abbreviated or even unnecessary. For the second group, further instruction in basic writing skills may be required prior to, or in conjunction with, training in more sophisticated strategy procedures.

In conclusion, the writing strategies and the corresponding training model described in this article provide an effective mechanism for affecting what LD students write and what they do during the process of composing. Nonetheless, our experience has made us sensitive to three important issues. First, the integrity of strategy interventions must be preserved. Erroneous or inadequate conceptualization and construction of strategy procedures or deficient learner and task analyses can result (and has resulted) in ineffective interventions. Strategy trainers should be knowledgedable of cognitive-behavior modification guidelines available in the literature (cf. Graham \& Harris, 1987a; Harris, 1982). Second, trainers should be mindful of how students internalize and employ composition strategies. Certain components or procedures may be disregarded and others overemphasized, or individual students may employ the same self-directed prompts in different ways. Finally, systematic planning should occur throughout training to ensure maintenance and generalization of strategic performance.

\section{REFERENCES}

Bereiter, C., \& Scardamalia, M. (1982). From conversation to composition: The role of instruction in a developmental process. In R. Glaser (Ed.), Advances in instructional psychology (Vol. 2, pp. 1-64). Hillsdale, NJ: Lawrence Erlbaum.

Bereiter, C., \& Scardamalia, M. (1983). Does learning to write have to be so difficult? In A. Freedman, I. Pringle, \& J. Yolden (Eds.), Learning to write: First language, second language (pp. 20-33). London: Longman's International.

Brown, A., Campione, J., \& Day, J. (1981). Learning to learn: On training students to learn from texts. Educational Researcher, 10, 14-21.

Brown, A., \& Palincsar, A. (1982). Inducing strategic learning from texts by means of informed, self-control training. Topics in Learning \& Learning Disabilities, 2, 1-17.

Deno, S., Marston, D., \& Mirkin, P. (1982). Valid measurement procedures for continuous evaluation of written expression. Exceptional Children, 48, 368-371. 
Deshler, D., Alley, G., Warner, M. , \& Schumaker, J. (1981). Instructional practices for promoting skill acquisition and generalization in severely learning disabled adolescents. Learning Disability Quarterly, 4, 415421.

Englert, C.S., \& Raphael, T. (in press). Constructing well-formed prose: Process, structure and metacognition in the instruction of expository writing. Exceptional Children.

Englert, C.S., \& Thomas, C.C. (1987). Sensitivity to text structure in reading and writing: A comparison of learning disabled and non-learning disabled students. Learning Disability Quarterly, 10, 93-105.

Graham, S. (1982). Composition research and practice: A unified approach. Focus on Exceptional Children, 14, 1-16.

Graham, S., \& Harris, K.R. (1987a). Improving composition skills of inefficient learners with self-instructional strategy training. Topics in Language Disorders, 7, 66-77.

Graham, S., \& Harris, K.R. (1987b). A components analysis of cognitive strategy training: Effects on learning disabled students' composition and self-efficacy. Manuscript submitted for publication.

Graham, S., \& Harris, K.R. (in press-a). Instructional recommendations for teaching writing to exceptional students. Exceptional Children.

Graham, S., \& Harris, K.R. (in press-b). Cognitive training: Implications for written language. In J. Hughes \& R. Hall (Eds.), Handbook of cognitive-behavioral approaches in educational settings. New York: Guilford.

Graham, S., \& Harris, K.R. (Eds.). (in press-c). Written language instruction and research [Special issue]. Exceptional Children.

Graham, S., \& MacArthur, C. (1987). [Improving learning disabled students' skills at revising essays produced on a word processor: Self-instructional strategy training]. Unpublished raw data.

Harris, K.R. (1982). Cognitive-behavior modification: Application with exceptional students. Focus on Exceptional Children, 15, 1-16.

Harris, K.R. (1985). Conceptual, methodological, and clinical issues in cognitive-behavioral assessment. Journal of Abnormal Child Psychology, 13, 373-390.

Harris, K.R. (1986a). Self-monitoring of attentional behavior versus selfmonitoring of productivity: Effects on on-task behavior and academic response rate among learning disabled children. Journal of Applied Behavior Analysis, 19, 417-423.

Harris, K.R. (1986b). The effects of cognitive-behavior modification on private speech and task performance during problem-solving among learning disabled and normally achieving children. Journal of Abnormal Child Psychology, 14, 63-77.

Harris, K.R., \& Graham, S. (1985). Improving learning disabled students' composition skills: Self-control strategy training. Learning Disability Quarterly, 8, 27-36.

Harris, K.R., \& Graham, S. (1987). [Improving learning disabled students' skills at generating essays: Self-instructional strategy training]. Unpublished raw data.

Harris, K.R., \& Graham, S. (in press). Self-instructional strategy training: Improving writing skills among educationally handicapped students. Teaching Exceptional Students.

MacArthur, C., \& Graham, S. (in press). Learning disabled students' composing under three methods of text production: Handwriting, word processing, and dictation. Journal of Special Education.

Meichenbaum, D. (1976). Cognitive-functional approach to cognitive factors as determinants of learning disabilities. In R. M. Knight \& D. J. Bakker (Eds.), The neuropsychology of learning disorders: Theoretical approaches (pp. 423-442). Baltimore: University Park Press.

Meichenbaum, D. (1977). Cognitive behavior modification: An integrative approach. New York: Plenum Press.

Moran, M. (1981). Performance of learning disabled and low achieving secondary students on formal features of a paragraph-writing task. Learning Disability Quarterly, 4, 271-280.
Nodine, B., Barenbaum, E., \& Newcomer, P. (1985). Story composition by learning disabled, reading disabled, and normal children. Learning Disability Quarterly, 8, 167-179.

Pressley, M., \& Levin, J.R. (in press). Elaborative learning strategies for the inefficient learner. In S.J. Ceci (Ed.), Handbook of cognitive, social, and neuropsychological aspects of learning disabilities. Hillsdale, NJ: Lawrence Erlbaum.

Scardamalia, M., \& Bereiter, C. (1986). Written composition. In M. Wittrock (Ed.), Handbook of research on teaching (3rd ed., pp. 778803). New York: Macmillan.

Schumaker, J., Deshler, D., Alley, G., \& Warner, M. (1983). Toward the development of an intervention model for learning disabled adolescents: The University of Kansas Institute. Exceptional Education Quarterly, 4, 45-74.

Wong, B.Y.L. (1985). Issues in cognitive-behavioral interventions in academic skill areas. Journal of Abnormal Child Psychology, 13, 425442 .

The ordering of author names for this article was determined alphabetically.

\section{Professional update}

\section{UPCOMING MEETINGS}

February 24-27, 1988

Association for Children and Adults with Learning Disabilities

International Conference

Las Vegas, Nevada

Contact: ACLD Inc.

4156 Library Road

Pittsburgh, PA 15234

(412) 341-1515

\section{March 28-April 1, 1988}

Council for Exceptional Children

Annual Convention

Washington, DC

Contact: Dept. of Professional Development, CEC 1920 Association Dr.

Reston, VA 22091-1589

(703) 620-3660 


\section{professional update}

\section{NEW BOOKS}

\section{How to Thrive, Not Just Survive}

\section{Edited by Rose-Marie Swallow and Kathleen Mary Heubner}

Subtitled "A Guide to Developing Independent Life Skills for Blind and Visually Impaired Children and Youths," this new manual was developed for everyone who is involved in the education of blind and visually impaired children, parents and family, teacher aides, house-parents, child-care workers, regular classroom teachers, support staff members, rehabilitation teachers and counselors, and special education teachers.

The book's strengths are in its specific strategies for the development of necessary skills in socialization, orientation and mobility, and leisure and recreational activities. The first section discusses daily living skills, emphasizing personal and household management, socially appropriate behaviors, and communication skills. The second section gives an overview of independent travel devices and techniques, as well as low-vision aids. The third section provides information on choosing and learning recreational/leisure activities. Helpful photos are included, along with a list of resources for more in-depth information on any specific facet.
This 100-page paperback book is available from the American Foundation for the Blind, 15 West 16th St., New York, NY 10011.

\section{Assessing and Managing Behavior Disabilities}

\section{Edited by Norris G. Haring}

Ths new book offers procedures and methods that teachers, administrators, and support personnel will find helpful in dealing with serious behavior disorders. The presentation of research data is balanced by relevant case studies and information on exemplary programs and practices. The chapters cover theories and models, controversial assessment issues, various program options, service delivery systems, and other topics of import.

Contributors to the book include James Kauffman, John Jewell, Hill Walker, Margaret McLaughlin, Gregory Williams, Thomas Lehning, and others. The information is specific enough to be applicable in formulating workable assessment and intervention programs for this population, from early childhood through adult.

In paperback, this 320-page book is published by the University of Washington Press, Seattle, WA 98145. 